\title{
Разработка компонентов корпоративной системы управления проектами с учетом стадии жизненного цикла организации
}

\author{
Яна Савченко ${ }^{1 *}$, Анна Харланова ${ }^{2}$ \\ ${ }^{1}$ Уральский государственный экономический университет, Екатеринбург, Россия \\ ${ }^{2}$ Фабрика Управляющих Проектами, Екатеринбург, Россия
}

\begin{abstract}
Информация о статье
Поступила в редакцию:

16.05.2020

Принята

к опубликованию:

17.07.2020

УДК 005.86, 005.041

JEL L29, M19

Ключевые слова:

жизненный цикл организации, модель, стадии, система управления проектами, компоненты
\end{abstract}

\section{Keywords:}

organization life cycle, model, stages, project management system, components

\begin{abstract}
Аннотация
В исследовании определены требования к моделям жизненного циикла организации, позволяющим сформировать адекватную корпоративную систему управления проектами и получить максимальный эффект от ее использования. Выявлены наиболее подходящче для поставленных ичелей модели жизненного илкла. Определен состав и содержание компонентов корпоративной системы управления проектами на разных стадиях жизненного циикла организации.
\end{abstract}

Development of the Corporate Project Management System Components Considering the Stage of the Organization Life Cycle

Yana Savchenko, Anna Kharlanova

\section{Abstract}

The application of various life cycle models in the company development is becoming more widespread. When a company realizes at what stage of its life cycle it is, it can adjust its behavior, avoid traps and develop the appropriate strategies. Relevant management decisions are to be made and specific management tools are required at each stage of the organization life cycle. Project management is no exception. A specific set of approaches and methods of project management is essential at each stage of the organization life cycle. A certain level of the project management system development is inherent to each stage of the organization life cycle. The organization life cycle theory and project management were the theoretical and methodological background of the investigation. The study presents the analysis of various models of the organization life cycle according to their features in the process of developing the corporate project management system and its individual components. The requirements to the life cycle model, which allows forming an adequate corporate project management system and get the maximum effect from its application,

* Aвтор для связи: 75karpenko@mail.ru

DOI: https://dx.doi.org/10.24866/2311-2271/2020-2/81-93 
were determined. The life cycle models that are most suitable for the set goals were identified. These were the Adizes life cycle model and the Chernov model. The requirements for the components of the corporate project management system at different stages of the organization's life cycle were specified. The study found that the implementation of project management system components is most effective in the period from the stage of "youth" to the stage of "aristocracy" in accordance with the model of the Adizes life cycle. It is at these stages that it is essential for the company to introduce the methodology and formalize project and program management processes. The necessity for setting up a full-fledged project management system for the company appears at the stage of "stability" and it is at this stage that it has all the resources required for implementing the system.

\section{Введение}

Развитие проектного управления стало тенденцией, присущей многим современным компаниям. Реализация стратегии развития, осуществление НИОКР, производство новых видов продукции, внедрение инновационных технологий, освоение национальных и международных рынков реализуются через проекты и требует формирования особых бизнес-процессов, связанных с проектной деятельностью. В конечном счете стабильно функционирующая организация сталкивается с необходимостью формирования и внедрения корпоративной системы управления проектами. Разработка и внедрение корпоративной системы управления проектами (далее - КСУП) является важным этапом формализации процессов управления проектами в организации. Для продуктивного использования КСУП важно оценивать необходимость данных изменений с учетом внутренней и внешней среды организации, в том числе стадии жизненного цикла.

Компания, развиваясь, проходит последовательно определенные стадии, которые формируют ее жизненный цикл. Управлению жизненным циклом организации посвящено достаточное количество работ зарубежных и отечественных авторов, таких как И. Адизес [1], Л.Е. Грейнер [2], Д.Б. Берг [3], Е.Н. Емельянов и С.Е. Поварницына [4], Д.В. Чернов [5]. Однако в данном исследовании мы ставим целью не подробное изучение этих моделей и их различий, а определение тех из них, которые позволят выбрать компоненты системы управления проектами, необходимые для внедрения на определенных стадиях жизненного цикла компании и позволят реализовать возможности этих компонентов максимально эффективно. Для достижения цели определен круг задач: оценить существующие модели жизненного цикла организации на их применимость при разработке КСУП; проанализировать степень влияния жизненного цикла организации на успешность внедрения и использования компонентов КСУП; определить какие компоненты КСУП уместно внедрять на разных стадиях жизненного цикла организации и в какой момент развития организации возникает необходимость в формировании полноценной КСУП.

\section{Применимость моделей жизненного цикла организации при разработке компонентов корпоративной системы управления проектами}

Корпоративная система управления проектами представляет собой комплекс взаимосвязанных компонентов: методологии управления проекта- 
ми, проектного офиса, информационной системы и системы мотивации [6-10]. Это сложный механизм, требующий большого внимания и определенных условий для начала формирования. В частности, успех внедрения КСУП, будет зависеть от реальной готовности организации к формализации процессов управления проектами и изменению организационной структуры, адаптации персонала к требованиям проектного менеджмента, внедрению специализированной информационной системы и встраиванию новой системы управления проектами в деятельность компании. Поэтому модель жизненного цикла организации, которую мы предполагаем использовать для выбора оптимального состава и наполнения компонентов КСУП, должна отвечать следующим требованиям:

- учитывать уровень формализации внешних и внутренних процессов в организации, так как это позволит оценить сложность внедрения корпоративной системы управления проектами;

- учитывать гибкость организационной структуры в целом, и в области управления проектами в частности;

- позволять оценить наличие, количество и сбалансированность сотрудников, способных участвовать во внедрении изменений, так как это позволит оценить сопротивление внедрению корпоративной системы управления проектами;

- учитывать размер организации;

- характеризовать способность организации к изменениям.

В качестве дополнительного условия применимости модели для наших целей можно отметить ее ориентированность на проектное управление.

Определим соответствие моделей жизненного цикла данным требованиям.

В модели Б. Ливехуда уровень формализации процессов в организации не учитывается. Уровень формализации процессов в организации учитывается в моделях Д.Б. Берга, Л.Е. Грейнера, И. Адизеса, Е.Н. Емельянова С.Е. Поварницыной, и Д.В. Чернова. Однако в модели Берга отсутствует подробное описание динамики формализации процессов в зависимости от стадии жизненного цикла. В моделях Л.Е. Грейнера, Е. Емельянова - С. Поварницыной и Д.В. Чернова уровень формализации процессов в организации учитывается не на всех этапах. В модели Л.Е. Грейнера он не учитывается на стадии «креативность», в модели Емельянова - Поварницыной на стадиях «Тусовка» и «Управление качеством».

Модель Берга частично описывает изменения в организационной структуре при этом методика оценки гибкости организационной структуры не представлена. Модель Б. Ливехуда основана на оценке систем и гибкость организационной структуры не учитывается. Модели Л.Е. Грейнера, И. Адизеса и Е.Н. Емельянова - С.Е. Поварницыной учитывают изменения гибкости организационной структуры на каждом из этапов жизненного цикла организации. Модель Д.В. Чернова учитывает изменения гибкости организационной структуры частично.

Модели Д.Б. Берга, Б. Ливехуда, Л.Е. Грейнера, Е.Н. Емельянова С.Е. Поварницыной и Д.В. Чернова не содержат инструментов и методик, позволяющих оценить количество и сбалансированность сотрудников, спо- 
собных участвовать во внедрении изменений. Подобная оценка в виде тестирования сотрудников и выявления «людей-витаминов» содержится только в модели И. Адизеса.

Необходимость учитывать размер организации при определении стадии жизненного цикла предполагают модели Л.Е. Грейнера, Е.Н. Емельянова С.Е. Поварницыной и И. Адизеса, однако в первых двух моделях отсутствует методика оценки для учета данных факторов. В описании стадий жизненного цикла, согласно модели И. Адизеса, размер организации учитывается на отдельных стадиях, что позволяет точнее охарактеризовать стадию жизненного цикла анализируемой организации.

Результаты анализа применимости моделей жизненного цикла организации для учета при разработке корпоративной системы управления и ее компонентов представлены в табл. 1.

Таблица 1

\section{Определение применимости моделей жизненного цикла организации} при разработке корпоративной системы управления проектами

\begin{tabular}{|c|c|c|c|c|c|}
\hline \multirow[b]{2}{*}{$\begin{array}{c}\text { Модель жиз- } \\
\text { ненного цикла } \\
\text { (ЖЦ) организа- } \\
\text { ции }\end{array}$} & \multicolumn{5}{|c|}{ Требование к модели (критерий оценки применимости) } \\
\hline & $\begin{array}{c}\text { Учитьввет } \\
\text { уровень фор- } \\
\text { мализации } \\
\text { процессов в } \\
\text { организации }\end{array}$ & $\begin{array}{c}\text { Учитьвает гиб- } \\
\text { кость организаци- } \\
\text { онной структурьв в } \\
\text { целом и в области } \\
\text { управления проек- } \\
\text { тами }\end{array}$ & $\begin{array}{c}\text { Оценивает коли- } \\
\text { чество и баланс } \\
\text { сотрудников, } \\
\text { способньх участ- } \\
\text { вовать во внедре- } \\
\text { нии изменений }\end{array}$ & $\begin{array}{c}\text { Учитьвьет } \\
\text { размер орга- } \\
\text { низации }\end{array}$ & $\begin{array}{c}\text { Учитьввет } \\
\text { способность } \\
\text { организации } \\
\text { кизменени- } \\
\text { ям }\end{array}$ \\
\hline $\begin{array}{c}\text { Модель } \\
\text { Д.Б. Берга }\end{array}$ & $\begin{array}{c}\text { Учитывает, } \\
\text { нет подробно- } \\
\text { го описания }\end{array}$ & $\begin{array}{l}\text { Частично описывает } \\
\text { изменения в органи- } \\
\text { зационной структуре }\end{array}$ & Не оценивает & Не учитывает & $\begin{array}{c}\text { Не учитыва- } \\
\text { ет }\end{array}$ \\
\hline $\begin{array}{c}\text { Модель } \\
\text { Б. Ливехуда }\end{array}$ & Не учитывает & Не учитывает & Не оценивает & Не учитывает & $\begin{array}{c}\text { Не учитыва- } \\
\text { ет }\end{array}$ \\
\hline $\begin{array}{c}\text { Модель } \\
\text { Л.Е. Грейнера }\end{array}$ & $\begin{array}{c}\text { Учитывает не } \\
\text { на всех стади- } \\
\text { ях ЖЦ }\end{array}$ & Учитывает & Не оценивает & $\begin{array}{l}\text { Предполагает } \\
\text { учет фактора, } \\
\text { методики нет }\end{array}$ & $\begin{array}{c}\text { Учитывает } \\
\text { не на всех } \\
\text { стадиях ЖЦ }\end{array}$ \\
\hline $\begin{array}{c}\text { Модель И. Ади- } \\
\text { зеса }\end{array}$ & Учитывает & Учитывает & Оценивает & $\begin{array}{c}\text { Учитывает на } \\
\text { отдельных } \\
\text { стадиях ЖЦ }\end{array}$ & Учитывает \\
\hline $\begin{array}{c}\text { Модель } \\
\text { Е.Н. Емельянова } \\
\text { - С.Е. Поварни- } \\
\text { цььной }\end{array}$ & $\begin{array}{c}\text { Учитывает не } \\
\text { на всех стади- } \\
\text { ях ЖЦ }\end{array}$ & Учитывает & Не оценивает & $\begin{array}{l}\text { Предполагает } \\
\text { учет фактора, } \\
\text { методики нет }\end{array}$ & $\begin{array}{c}\text { Учитывает } \\
\text { не на всех } \\
\text { стадиях ЖЦ }\end{array}$ \\
\hline $\begin{array}{c}\text { Модель } \\
\text { Д.В. Чернова }\end{array}$ & $\begin{array}{c}\text { Учитывает не } \\
\text { на всех стади- } \\
\text { ях ЖЦ }\end{array}$ & Частично учитывает & Не оценивает & Не учитывает & $\begin{array}{c}\text { Учитывает } \\
\text { не на всех } \\
\text { стадиях ЖЦ }\end{array}$ \\
\hline
\end{tabular}

Источник: составлено авторами по [1-7]

Представленный в табл. 1 анализ соответствия моделей жизненного цикла организаций вышеперечисленным критериям, позволил определить модели, которые мы может использовать при формировании и внедрении отдельных компонентов КСУП и системы в целом.

Модель жизненного цикла Д.В. Чернова соответствует не всем критериям. Модели Д.Б. Берга и Б. Ливехуда не позволяют учесть размер организации и оценить кадры и способность организации к изменениям. Модель жизненного цикла организации Л.Е. Грейнера не всегда учитывает уровень формализации процессов, не содержит способ оценки кадров, механизм 
оценки размера организации и дальнейшего использования этих данных. Модель Е.Н. Емельянова - С.Е. Поварницыной учитывает уровень формализации не на всех стадиях жизненного цикла, способ оценки кадров и использования данных о размере организации для определения стадии жизненного цикла отсутствуют, способность организации к изменениям учитывается не на всех этапах.

Таким образом, оценив модели жизненного цикла, можно сделать вывод, что при разработке элементов КСУП с учетом стадии жизненного цикла наиболее полные результаты дает использование модели И. Адизеса, так как данная модель позволяет учитывать кадровый потенциал организации. Кроме того, только для данной модели разработана система тестирования ключевых сотрудников организации для определения стадии жизненного цикла, что позволяет получить более точные результаты при исследовании.

Так как оценка применимости моделей жизненного цикла организации проводилась для определения стадий жизненного цикла, позволяющих успешно внедрить КСУП и полноценно сформировать требуемые на каждой стадии ЖЦ компоненты системы, то важно, чтобы модель жизненного цикла организации была связана с проектной деятельностью организации.

Учитывая, что модель Д.В. Чернова в наибольшей степени описывает изменения в проектной деятельности по мере прохождения организацией стадий жизненного цикла, при разработке КСУП целесообразно учитывать стадию жизненного цикла, определенную в соответствии с данной моделью.

Использование иных моделей жизненного цикла организации при внедрении КСУП может быть полезно в случае, если необходимо учесть анализ каких-либо отдельных сфер деятельности или подразделений организации, тип руководства организацией, организационную структуру, внутренние связи между подразделениями или специфику выполнения ключевых задач организации.

Таким образом, при разработке рекомендаций по внедрению компонентов КСУП, необходимо использовать модели жизненного цикла организации И. Адизеса или Д.В. Чернова.

Определение стадии жизненного цикла организации по модели И. Адизеса проводится путем тестирования ключевых сотрудников организации в соответствии с анкетой и ключом к диагностике оценки жизненного цикла организации по методике И. Адизеса. Определение стадии жизненного цикла организации по модели Д.В. Чернова проводится путем соотнесения реального состояния организации и описываемых процессов и изменений, согласно модели жизненного цикла.

\section{Анализ степени влияния жизненного цикла организации}

\section{на успешность внедрения и использования компонентов КСУП}

Авторы по-разному оценивают степень влияния жизненного цикла организации на успешность внедрения и использования КСУП.

Логинов М.П. и Марков А.А. рассматривают внедрение КСУП с учетом стадии жизненного цикла, как внедрение системы управления проектами с учетом уровня зрелости организации. Авторы отмечают, что жизненный цикл организации предполагает прохождение этапа развития, для которого харак- 
терны увеличение объемов выпускаемой продукции, а также количества реализуемых проектов и степени их сложности. При этом объединение отдельных проектов в программы позволяет получить дополнительный эффект от скоординированной, совместной их реализации на общей производственной и технологической базе [11].

Авторы указывают на наличие связи между уровнем зрелости управления проектами и стадиями жизненного цикла организации. Так, Загузкин Н.Н. отмечает, что «в большинстве моделей зрелости, применимых и в процессном, и в проектом типах организаций, используется пятиуровневая система градации, сходная по числу уровней (стадий) с моделью жизненного цикла Л. Грейнера. При этом, и модель Грейнера Л., и модели зрелости основываются на эволюционном развитии и недопустимости «пропуска» этапов развития» [12].

К.В. Левин [13] описывает связь между моделью жизненного цикла организации Д.В. Чернова и моделью зрелости Г. Керцнера [14]. Султанов И.А. указывает, что на восходящих стадиях жизненного цикла компании и возникает, как правило, КСУП, целями которой является повышение эффективности инвестиционной практики [15]. И.О. Недавний [16] описывает этапы совершенствования проектного управления в компании в зависимости от стадий жизненного цикла по модели И. Адизеса и динамику доминирования групп бизнес-процессов: проектной, клиентской, учетной эффективности. Д.В. Чернов представляет модель жизненного цикла свойственную российскому бизнесу [5]. Он выделяет структуру управленческой деятельности для каждой стадии жизненного цикла, определив доли оперативного, операционного и проектного управления.

Обобщая результаты анализа трудов, посвященных проблематике проектного управления на стыке с теорией жизненного цикла организации можно сделать вывод, что внедрение компонентов КСУП возможно только на отдельных этапах жизненного цикла. Поэтому логическим продолжением данного исследования является анализ возможностей внедрения и использования элементов КСУП в зависимости от стадии жизненного цикла, на которой находится организация. Для этих целей мы будем использовать модель жизненного цикла организации: И. Адизеса.

Для оценки возможности внедрения системы управления проектами необходимо понимать потребность организации в управленческих и административных ресурсах, поскольку команда управления проектом является одним из ключевых факторов успешной его реализации.

Для внедрения и работоспособности КСУП в организации должны быть сотрудники, способные внедрять, использовать и поддерживать рабочее состояние компонентов системы. В модели жизненного цикла И. Адизеса такие люди получили название люди-витамины. И. Адизес выделяет четыре роли менеджера, необходимых для эффективного функционирования организации, называя их витаминами: P (purpose) - производитель результатов, A (administration) - администратор, E - (enterpreneur) - предприниматель, I (integration) - интегратор. Люди-витамины P нужны для обеспечения результатов производственных процессов, т.е. удовлетворения потребности клиента. Администраторы А координируют деятельность и поддерживают 
порядок в организационных процессах. Предприниматели Е необходимы для продвижения новых идей, без которых не будет развития организации, инициируют изменения в организации. Интеграторы I обеспечивают жизнеспособность организации как единого механизма.

Наличие или отсутствие людей-витаминов может повлиять не только на эффективность функционирования организации, но и на успешность внедрения компонентов корпоративной системы управления проектами.

Внедрение КСУП в организации само по себе является сложным комплексным, длящимся проектом. Поэтому в ходе внедрения КСУП могут возникать сложности при формулировании и согласовании четких целей, требований к конечным результатам и критериям успеха данного проекта [17].

Создать необходимые инструменты и механизмы для внедрения и полноценного использования КСУП и ее компонентов, структурировать, определять точные требования к конечным результатам и критериям успеха и контролировать данный процесс могут люди-витамины А, так как данный витамин сконцентрирован на администрировании, систематизации и регламентировании. При нормальном развитии организации данный витамин в достаточном количестве должен присутствовать на стадиях: юность, зрелость, стабильность, аристократизм (пожилой возраст), ранняя бюрократизация (пенсионный возраст), бюрократизация (старость) [1].

Отношение сотрудников к изменениям, в том числе внедрению элементов КСУП играет большую роль. Невнимание к фактору организационного сопротивления сотрудников может привести к провалу проекта внедрения КСУП [5]. Важно, чтобы нововведения принимались сотрудниками организации, повлиять на мнение людей могут люди-витамины I, так как именно они заставляют людей действовать сообща. При нормальном развитии организации данный витамин в достаточном количестве должен присутствовать на стадиях: стабильность и аристократизм. При этом в некоторой степени данный витамин присутствует на стадиях: выхаживание, младенчество, детство, юность, расцвет (зрелость).

Внедрение изменений в организации, в том числе внедрение компонентов КСУП можно достичь путем привлечения внешних консультантов или за счет ресурсов организации. В последнем случае большое значение имеет «интрапренерство». Интрапренерство - создание в организации условий для выдвижения новаторских, предпринимательских идей: выделение ресурсов, всесторонняя помощь для реализации идеи и ее использования [18]. Важно, чтобы в компании были люди-витамины Е, так как именно они выдвигают новаторские идеи, что может помочь при внедрении элементов КСУП.

При внедрении изменений, в том числе компонентов КСУП важно сохранить или усовершенствовать качество бизнес-процессов в организации, ее производительность [13], так как иначе внедрение корпоративной системы не только не усовершенствует качество и скорость бизнес-процессов, но и ухудшит качество операционной деятельности компании. Для поддержания бизнес-процессов в рабочем состоянии необходимы люди-витамины Р, так как именно они создают результаты, которые позволяют организации существовать в краткосрочной перспективе. 
Таким образом, можно сделать вывод, что наличие в организации людей-витаминов необходимо при внедрении элементов корпоративной системы управления проектами.

На стадиях ранняя бюрократизация, бюрократизация и смерть отсутствуют люди-витамины Р, E, I, организация перестает развиваться, поэтому попытки внедрить корпоративную систему управления проектами или ее элементы приведет к еще большей бюрократизации процессов и будет неэффективно.

Следовательно, эффективное внедрение компонентов КСУП возможно в том случае, когда в организации присутствуют все четыре вида людейвитаминов. К этим стадиям относятся: выхаживание (зарождение), младенчество, детство (давай-давай), юность, расцвет (зрелость), стабильность и аристократизм (табл. 2).

Таблица 2

Наличие человеческих ресурсов для эффективного внедрения компонентов КСУП по модели И. Адизеса

\begin{tabular}{|l|c|c|c|c|}
\hline $\begin{array}{c}\text { Стадия ЖЦ организа- } \\
\text { ции }\end{array}$ & $\begin{array}{c}\text { Наличие } \\
\text { людей- ви- } \\
\text { таминов А }\end{array}$ & $\begin{array}{c}\text { Наличие } \\
\text { людей- ви- } \\
\text { таминов I }\end{array}$ & $\begin{array}{c}\text { Наличие лю- } \\
\text { дей- витами- } \\
\text { нов P }\end{array}$ & $\begin{array}{c}\text { Наличие } \\
\text { людей- ви- } \\
\text { таминов Е }\end{array}$ \\
\hline Зарождение & + & + & + & ++ \\
\hline Младенчество & + & + & ++ & + \\
\hline Детство & + & + & ++ & ++ \\
\hline Юность & ++ & + & ++ & ++ \\
\hline Рассвет (зрелость) & ++ & + & ++ & ++ \\
\hline Стабильность & ++ & ++ & + & - \\
\hline Аристократизм & ++ & ++ & - & - \\
\hline Ранняя бюрократизация & ++ & + & - & - \\
\hline Бюрократизация & ++ & - & - & + \\
\hline Смерть & - & - & + & + \\
\hline
\end{tabular}

Примечание: + частичное наличие ресурса; ++ наличие ресурса в достаточном количестве Источник: составлено авторами по [1]

На стадиях выхаживание и младенчество происходит зарождение бизнес-идеи и создание организации, первичное выстраивание ключевых организационных процессов. На стадии «давай-давай» высшим приоритетом становится рост продаж. Так как управление проектами в целом, а, следовательно, и внедрение КСУП в частности, основано на «предварительной коллегиальной разработке комплексно-системной модели действий по достижению оригинальной цели и направленный на реализацию этой модели» [19], то внедрение КСУП на данных стадиях не будет эффективным, так как организационная структура и процессы еще не сформированы. В организации отсутствует четкая структура, формально-закрепленные правила, регламенты. Кроме того, важной чертой данной стадии является контроль основателя, что приводит к его перегруженности задачами и потребности в делегировании. Можно сделать вывод, что на данных стадиях у руководства организации недостаточно ресурсов для внедрения компонентов КСУП и внедрение последних до стадии «юность» нецелесообразно. 
Таким образом, успешность внедрения компонентов КСУП наиболее вероятна в следующем промежутке развития организации: со стадии «юность», до стадии «аристократизм» (табл. 3).

Таблиия 3

\section{Внедрение компонентов КСУП на разных стадиях жизненного цикла} организации по модели И. Адизеса

\begin{tabular}{|c|c|c|c|c|}
\hline \multirow{2}{*}{$\begin{array}{c}\text { Стадия ЖЦ } \\
\text { организации }\end{array}$} & \multicolumn{4}{|c|}{ Компонент корпоративной системы управления проектами } \\
\cline { 2 - 5 } & $\begin{array}{c}\text { Методология } \\
\text { проектного } \\
\text { управления }\end{array}$ & $\begin{array}{c}\text { Проектный } \\
\text { офис }\end{array}$ & $\begin{array}{c}\text { Информационная } \\
\text { система управления } \\
\text { проектами (ИСУП) }\end{array}$ & $\begin{array}{c}\text { Система моти- } \\
\text { вации персона- } \\
\text { ла в проектной } \\
\text { деятельности }\end{array}$ \\
\hline Юность & Формируется & $\begin{array}{c}\text { Начинает фор- } \\
\text { мироваться при } \\
\text { необходимости }\end{array}$ & $\begin{array}{c}\text { Внедрение элементов, } \\
\text { поответствующих } \\
\text { потребняя органи- } \\
\text { зации }\end{array}$ & Формируется \\
\hline $\begin{array}{c}\text { Рассвет (зре- } \\
\text { лость) }\end{array}$ & $\begin{array}{c}\text { Формируется или } \\
\text { Сформирована }\end{array}$ & Сформирован & Развивается & Сформирована \\
\hline $\begin{array}{c}\text { Стабильность } \\
\text { Аристокра- } \\
\text { тизм }\end{array}$ & Совершенствуется & $\begin{array}{c}\text { Совершенству- } \\
\text { ется }\end{array}$ & Совершенствуется & $\begin{array}{c}\text { Совершенству- } \\
\text { ется }\end{array}$ \\
\hline
\end{tabular}

Источник: составлено авторами по [7, 9, 15, 17, 20]

Формирование ролевой структуры (определение полномочий и ответственности персонала, выбор системы мотивации и согласование принципов формирования команд проекта [9]) наиболее успешно будет реализовано на стадии «юность», так как именно на этой стадии, согласно модели И. Адизеса организация должна перейти от предпринимательского менеджмента к профессиональному управлению. Кроме того, на данной стадии должен пройти процесс делегирования полномочий, следовательно, формирование ролевой структуры может стать частью данных процессов. Наличие в организации людей-витаминов А и Е позволит с одной стороны полностью регламентировать данные процессы, а с другой стороны реализовать их в соответствии с изменчивостью внешней и гибкостью внутренней среды организации.

Предпосылки создания специализированного подразделения (проектного офиса) могут начинать формироваться еще на стадии юность, однако завершение данного процесса и создание в организации проектного офиса наиболее успешно на стадии «расцвет». На данной стадии достаточно человеческих ресурсов, необходимых для внедрения данного компонента корпоративной системы управления проектами, а именно:

1. Производственных ресурсов (в том числе люди-витамины Р), чтобы организация сохраняла работоспособность;

2. Административных ресурсов (в том числе люди-витамины А) для регламентации создания, деятельности и положения в организации проектного офиса; 
3. Предпринимательских ресурсов (в том числе люди-витамины - Е), для предложения идей и поиска возможностей внедрения, а также сохранения позиции на рынке за счет предугадывания изменений;

4. Человеческих ресурсов (в том числе люди-витамины - I), для создания атмосферы и системы ценностей, которая позволит сотрудникам действовать сообща и довести мероприятия до конца.

При создании проектного офиса важен не только баланс людейвитаминов. Большую роль играет также наличие в организации персонала, специализирующегося на проектном управлении. Важным фактором успеха здесь выступает процесс подбора и обучения персонала.

Автоматизированную (информационную) систему управления проектами, как и иные компоненты КСУП рекомендуется внедрять поэтапно [16]. При внедрении ролевой структуры внедрять программы, позволяющие упростить и ускорить обмен данными между участниками проектной деятельности. При внедрении офиса управления проектами - специализированную программу управления проектами. Кроме того, на стадиях юность и расцвет, потребности в виде информационной системы управления проектами могут меняться, необходимо внедрять элементы, соответствующие потребностям организации, при этом учитывая ее возможности, в том числе финансовые. К стадии стабильность элементы информационной системы управления проектами будут, возможно, окончательно определены, а их работа налажена. На стадии аристократизм возможно обновление программ, входящих в информационную систему, но данное обновление будет включать только совершенствование программного обеспечения, а не процессов управления проектами.

Разработка и согласование методологии управления проектами может начать формироваться на стадии юность, но в виде распределения ролей при управлении проектом. При этом методология на данной стадии может быть неформализованной. На стадии «расцвет» методология должна быть принята всеми участниками проектной деятельности, при этом она может оставаться неформализованной (все участники управления проектами реализуют их в соответствии с принятыми правилами, которые при этом, могут нигде не прописываться, а передаваться от руководителей к подчиненным в устной форме) или частично формализованной для отдельных процессов.

На стадии «стабильность» методология управления проектами будет связана с внедренной ИСУП. Данные элементы станут дополнять друг друга и будут работать согласованно. Таким образом, на стадии «стабильность» у компании формируется полноценная КСУП, которая совершенствуется при возникновении потребности. На стадии аристократизм важно не допустить бюрократизацию внедренной методологии управления проектами. Методология должна сохранять гибкость и адаптивность под определенный проект.

\section{Выводы}

В результате проведенного исследования было определено, что при принятии решения о внедрении корпоративной системы управления проектами или ее отдельных компонентов имеет смысл учитывать стадию жизненного цикла, на которой находится организация. При этом было установлено, что для этих целей можно использовать только модель И. Адизеса или мо- 
дель Д.В. Чернова. Потребность в формировании компонентов КСУП возникает в организации не сразу, а по мере ее развития и появления необходимых для внедрения системы и ее компонентов ресурсов. Потребность в формализации проектного управления возникает в соответствии с моделью И. Адизеса на стадии «юность», а полноценная корпоративная система должна быть сформирована на стадии «стабильность».

Результаты исследования могут быть интересны проектноориентированным организациям, а также компаниям, реализующим большое количество проектов, и позволят создать эффективную систему управления проектной деятельностью на каждой стадии жизненного цикла компании.

\section{Список источников / References}

1. Адизес И. Как понять свой стиль управления и эффективно общаться с носителями иных стилей. Москва, Альпина Паблишерз, 2011. 259 с. [Adizes, I. Kak ponyat svoy stil upravlenia I effectivno obshhatsya s nositeliami inyih stiley [Leading The Leaders. How to Enrich Your Style of Management] / Moscow, Alpina Publishers, 2011. 259 p.]

2. Грейнер Л. Е. Эволюция и революция в процессе роста организаций. Вестник Санкт - Петербургского университета. Серия Менеджмент. 2002. №4. С. 76-94 [Greiner L.E. Evolyutsiya i revolyutsiya v protsesse rosta organizatsiy [Evolution and revolution in organization growth process]. Vestnik Sankt.- Peterburgskogo universiteta. Seriya Menedzhment = Bulletin of the St. Petersburg University. Management series. 2002, no. 4. pp. 76-94.]

3. Берг Д.Б. Ульянова Е. А., Добряк П.В. Модели жизненного цикла. Екатеринбург: Изд-во Урал. ун-та, 2014. 74 с. [Berg D.B. Ulyanova E.A., Dobryak P.V. Modeli jiznennogo tsikla [Life cycle models]. Ekatirinburg: Izd-vo Ural un-ta, 2014. 74 p.]

4. Емельянов Е.Н. Поварницына С.Е. Психология бизнеса. Москва, АРМАДА, 1998. 511 c. [Emelyanov E.N. Psihologiya biznesa [Business psychology]. Moscow, ARMADA, 1998. 511 p.]

5. Чернов Д.В. Волна или Как управлять корпоративными коммуникациями в России, когда все меняется. Москва, «Коммуникационная группа АГТ», 2008. 264 с. [Chernov D. V. Volna ili Kak upravlyat korporativnymi kommynikaciyami v Rossii, kogda vso menyaetsya [Wave or How to manage corporate communications in Russia, when everything changes], Moscow, AGT Communication Group, 2008. 264 p.]

6. Береговенко А. Корпоративная система управления проектами. Пособие для настройки успешного бизнеса, реальные кейсы. Москва, Издательские решения, 2018. 70 c. [Beregovenko A. Korporativnaya Sistema ypravleniya proektami. Posobie dlya nastroiki yspeshnogo biznesa, realnye keisy [Corporate project management system. A guide to setting up a successful business, real cases] Moscow, Izdatelskie resheniya, 2018.70 p.]

7. Богданов В.В. Управление проектами. Корпоративная система - шаг за шагом. Москва Манн, Иванов и Фербер, 2013. 248 с. [Bogdanov V.V. Upravlenie proektami. Korporativnaya Sistema - shag za shagom [Project management. Corporate system step by step] Moscow, Mann, Ivanov and Ferber, 2013. 248 p.]

8. Дадашев Д.В. Внедрение корпоративной системы управления проектами в строительной компании как основа повышения качества ее функционирования. Современные проблемы науки и образования, 2015, №1-1. - URL: http://scienceeducation.ru/ru/article/view?id=18976 [Dadashef D.V. Vnedrenie korporativnoi sistemiy ypravliniya proektami $\mathrm{v}$ stroitelnoi kompanii kak osnova poviysheniya kachestva ee fynkcionirovaniya [I mplementation of a corporate project management 
system in a construction company as a basis for improving the quality of its functioning]. Sovremennyye problemy nauki i obrazovaniya $=$ Modern problems of science and education.-2015. no. 1-1.]

9. Козлов А.С. Методология управления Портфелем Программ и Проектов. Москва, ФЛИНТА, 2011. 194 с. [Kozlov A.S. Metodologiya ypravleniya Portfelem Programm i Proektov [Program Portfolio Management Methodology]. Moscow, FLINTA, 2011. 194 p.]

10. Костерин Е. В. Особенности разработки и внедрения корпоративной системы управления проектом. Вестник Гуманитарного Университета, 2018, №1(20), сс. 39-46. [Kosterin E.V. Osobennosti razrabotki i vnedreniya korporativnoy sistemiy upravleniya proektom [Features of the development and implementation of a corporate project management system]. Vestnik Gumanitarnogo Universiteta $=$ Bulletin of the University of the Humanities. - 2018, no. 1(20), p. 39-46.]

11. Марков А.А. Логинов М.П. Оценка зрелости проектного управления. Bonpocbl управления, 2018, №3(52), сc. 133-141 [Markov A.A., Loginov M.P. Ocenka zrelosti proektnogo ypravleniya [Project Management Maturity Assessment]. Voprosy upravleniya $=$ Questions of management, 2018, no. 3(52), pp.133-141]

12. Загускин Н.Н. Сравнительная характеристика моделей зрелости управления процессами, проектами, знаниями организаций-участников иск по стадиям их трансформационного развития. Успехи современного естествознания, 2014, № 1, cc. 78-81 [Zaguskin N.N. Sravnitel'naya kharakteristika modeley zrelosti upravleniya protsessom, proyektami, znaniyami organizatsiy-uchastnikov protsessa transformatsii razvitiya [Comparative charactristics of maturity model for management of processes, projects, knowledge of the organization subjects of icc by stages of their transformations]. Uspekhi sovremennogo yestestvoznaniya =Advances in current natural sciences, 2014, no. 1, pp. 78-81]

13. Левин К.В. Развитие системы управления проектами в организации среднего бизнеса. URL:http://jazzsoft.kz/razvitie-sistemy-upravlenija-proektami-v-organizaciisrednego-biznesa-2/ [Levin K.V. Razvitie sistemy upravleniya proektami v organizatcii srednego biznesa [Development of a project management system in the organization of medium-sized businesses]

14. Керцнер Г. Стратегическое управление в компании. Модель зрелого управления проектами. Москва, ДМК Пресс, 2018. 321 с. [Kercner G. Strategicheskoe ypravlenie v kompanii. Model zrelogo ypravleniya proektami [Strategic management in the company. Mature Project Management Model]. Moscow, DMK Press, 2018. 321 p.]

15. Султанов И.А. Формирование систем управления проектами. Портал Projectimo.ru. http://projectimo.ru/upravlenie-proektami/korporativnaya-sistemaupravleniya-proektami.html [Syltanov I.A. Formirovanie sistem ypravleniya proektami [Formation of project management systems]. Portal Projectimo.ru.]

16. Недавний И.О. Эффективное применение информационных систем или как стать суперкомпанией. Портал Управление производством, 15.09.2014, http://www.uppro.ru/library/information_systems/managemen/ superkompaniya.html [Nedavnyi I.O. Effektivnoe primenenie informatcionny system ili kak stat syperkompaniei [Effective application of information systems or how to become a supercompany]. Portal Upravleniye proizvodstvom = Production Management Portal, 2014.]

17. Мухтарова К.С. Управление проектами. Алматы, Казах. нац. ун-т им. аль-Фараби. - Қазақ ун-ті, 2016. 320 с. [Myhtarova K.S. Upravlenie proektami [Project management], Almaty, Kazakh. nat. un-t named al-Farabi, 2016. 320 p.]

18. Акимова О.Е., Волков С.К., Митрофанова И.В. и др. Инновационное предпринимательство в России: тренды, инструменты и потенциал развития. - Москва; Берлин: Директ-Медиа, 2019. 126 с. [Akimova O.E., Volkov S.K., Mitrofanova I.V. 
Innovatcionnoe predprinimatelstvo $v$ Rossii: trendy, instrymenty $i$ potentcial razvitiya [Innovative Entrepreneurship in Russia: Trends, Tools and Development Potential]. Moscow; Berline: Direct-Media, 2019. 126 p.]

19. Денисенко В. И. Управление проектами. Владимир, Изд-во ВлГУ, 2015. - 108 с. [Upravlenie proektami [Project management]. Vladimir VLGU, 2015. 108 p.]

20. Болотова К.Р., Грошева Н.Б. Создание проектного офиса как инструмента реализации инновационных проектов. Бизнес-образование в экономике знаний, 2015. № 2. - cc. 3-5. [Bolotova K.R., Grosheva N.B. Sozdanie proektnogo ofisa kak instrymenta realizacii innivatcionnyh proektov [Bolotova K.R., Grosheva N.B. Creating a project office as a tool for implementing innovative projects]. Biznes-obrazovaniye $\mathrm{v}$ ekonomike znaniy $=$ Business-education in knowledge economics, 2015, no. 2, pp. 3-5.]

\section{Сведения об авторах / About authors}

Савченко Яна Валерьевна, кандидат экономических наук, доцент, доцент, кафедры экономической теории и корпоративной экономики, Уральский государственный экономический университет. 620144 Россия, г. Екатеринбург, ул. 8 Марта/Народной воли, д. 62/45.

E-mail:75karpenko@mail.ru

Yana V. Savchenko, Candidate of Sciences (Economics), Associate Professor of Economic Theory and Corporate Economics Dept., Ural State University of Economics. 62/45 8 Marta/Narodnoy Voli St., Yekaterinburg, Russia 620144.E-mail: 75karpenko@mail.ru.

Харланова Анна Игоревна, менеджер проектов, НОУ ДПО «Фабрика Управляющих Проектами». 620144 Россия, г. Екатеринбург, ул. Циолковского, д. 27, офис 402.

E-mail: harlanova.anna@bk.ru

Anna I. Kharlanova, Project Manager, "Factory Project Managers". Office 402, 27, Tsiolkovsky St., Yekaterinburg, Russia 620144. E-mail: harlanova.anna@bk.ru 